\title{
Winter aggregations, Dehnel Effect, and habitat relations in the Suisun shrew Sorex ornatus sinuosus
}

\author{
Warren S. T. HAYS* and William Z. LIDICKER Jr
}

\begin{abstract}
Hays W. S. T. and Lidicker W. Z. Jr 2000. Winter aggregations, Dehnel Effect, and habitat relations in the Suisun shrew Sorex ornatus sinuosus. Acta Theriologica 45: 433-442.

A live-trapping study on Suisun shrews Sorex ornatus sinuosus Grinnell, 1913, an endangered subspecies, was performed during the non-breeding season along the edge of a tidal marsh in California. During the winter, these shrews lived in distinct social aggregations composed of a single adult male, several adult females, and subadults. These groups remained stable even when the adult male died. As the breeding season approached, these groups were invaded by numerous adult males resulting in a nearly complete change in group membership. At the end of the breeding season, adult body mass declined by 30 to $40 \%$ (Dehnel Effect). Shrews reached high densities along the marsh/grassland ecotone, but the precise locations of social groups seemed unrelated to the presence of particular plant species or to the amphipod food supply. Subadult males wintered mostly outside of social groups in the marsh below high tide level. Conservation efforts need to focus on preserving the tidal marsh ecotone without promoting contact with the upland subspecies.

Museum of Vertebrate Zoology, University of California, Berkeley, California 94720, USA

Key words: Sorex ornatus, social structure, Dehnel Effect, habitat relations, breeding season
\end{abstract}

\section{Introduction}

The Suisun shrew Sorex ornatus sinuosus Grinnell, 1913 is a distinctive subspecies of the ornate shrew with an extremely limited geographic distribution. It was originally described as a separate species, but recently is classified as a subspecies because of intergradation with S. o. californicus. The Suisun shrew is restricted to the tidal saltmashes along a part of the northern edge of the San Francisco Bay estuary (Grizzly Island and vicinity on north side of Suisun Bay). It is considered to be a "species of special concern" by the State of California (Williams 1986) because of habitat losses and possibly an increased rate of hybridization with $S$. o. californicus that lives in adjacent uplands. S. o. sinuosus differs from californicus in having a strongly melanistic pelage coloration, slightly

\footnotetext{
* Present address: Department of Biology, Hawaii Pacific University, Honolulu, HI 96813, USA, e-mail: whays@hpu.edu
} 
larger body size, different habitat requirements, a different array of food species, and apparently in aspects of behavior. Little is known regarding the ecology and behavior of ornate shrews in general (Owen and Hoffmann 1983, Hoffmann 1999). Suisun shrews have been studied by Rudd (1953, 1955a, b), Johnston and Rudd (1957), Newman and Rudd (1978a, b), Rust (1978), and Williams (1983).

The research reported here was begun as an effort to learn more of this endangered form's habitat requirements and other life history features that might prove useful in future land management decisions. Unexpectedly, we discovered an apparently unusual social structure in this shrew that expands our understanding of the range of social behavior possible in soricine shrews (Rychlik 1998), and raises numerous questions about the evolution of social behavior in these small-brained and short-lived mammals. Moreover, we present evidence for a Dehnel Effect (Dehnel 1949, Crowcroft and Ingles 1959, Pucek 1963) which is not anticipated to occur in shrews inhabiting such a seasonally equitable climate (Pucek 1970, Rychlik 1998). Finally, we contribute to our understanding of the habitat requirements, food habits, and seasonal reproductive patterns in this shrew, all of which should be helpful in future efforts to conserve this unique subspecies.

\section{Study area}

Fieldwork was carried out at the Rush Ranch, owned by Solano County Farmlands and Open Space Foundation, on the north side of Suisun Bay, Solano County, California, during 1989 and 1990. The study area was in an ecotone between ungrazed annual grassland and undiked tidal marsh. This ecotone was 20 to $70 \mathrm{~m}$ wide, and about $8 \mathrm{~km}$ long. It was flooded completely only a few times per year. A centrally located $100 \mathrm{~m}$ section was used for the trapping grid. It consisted of a mosaic of vegetated patches 10 to $40 \mathrm{~cm}$ in height and open salt pannes (Fig. 1).

Dominant plants were pickleweed Salicornia virginica, jaumea Jaumea carnosa, saltgrass Distichlis spicata, arrowgrass Triglochin maritinum, lemongrass Lepidium sp., and dodder Cuscuta salina. The soil of this ecotone remained moist even during low tides and rainless periods, and was covered by a dense layer of matted vegetation which was riddled with runways. Small mammal burrows were also abundant. The tidal marsh below the ecotone was extensive (100 to $500 \mathrm{~m}$ wide), and was flooded twice daily by the tides. Dominant plants here were bulrush Scirpus sp., arrowgrass and jaumea. High densities of amphipods (hundreds per square meter) were present on the soil surface at all seasons. Suisun shrews readily fed on them in captivity. The other common species of small mammal in the ecotone was the saltmarsh harvest mouse Reithrodontomys raviventris, and California voles Microtus californicus were found occasionally. All three of these species also were found in low densities in the tidal marsh. Potential predators included five species of raptors as well as foxes (probably Vulpes vulpes), skunks Mephitis mephitis, and gopher snakes Pituophis melanoleucus.

\section{Material and methods}

Small Sherman live traps (20 $\mathrm{cm}$ in length) were modified so as to require monitoring only once a day. Large plastic jars were attached to the traps, and these contained bedding and live food (mealworms Tenebrio sp.) to prevent hypothermia and starvation (Hays 1998). Traps were covered with boards for protection from rain and sun. This arrangement was successful as trap mortality was 


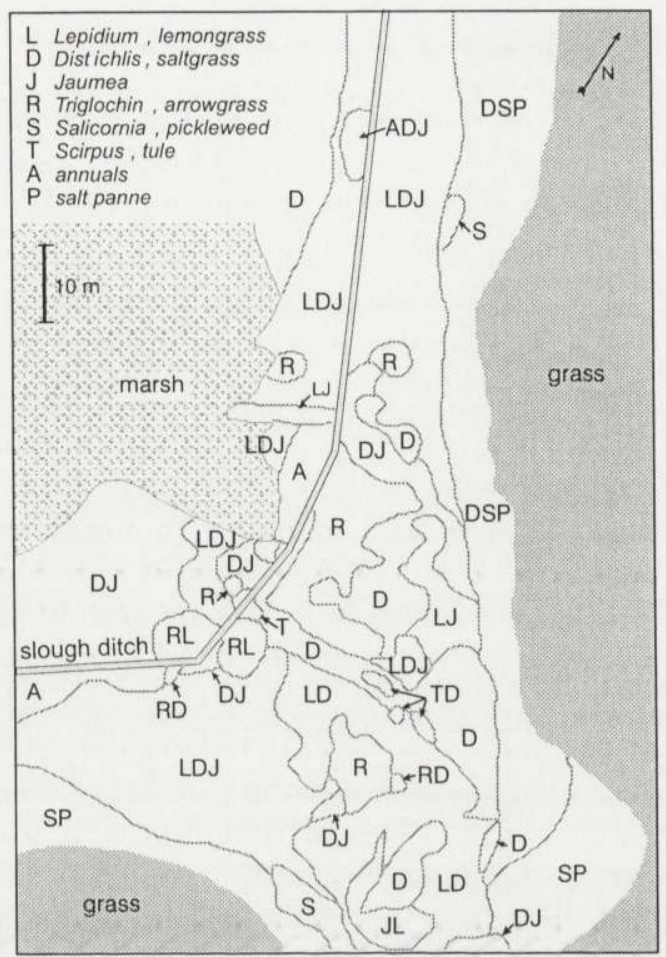

Fig. 1. Map of study area (in Rush Ranch, Solano Co., California) showing vegetation patches characterized by the dominant plant species.

only $1.0 \%$. During 31 August to 12 October 1989 traps were placed along a lengthy section $(1.8 \mathrm{~km})$ of the ecotone to determine where the shrews occurred with respect to vegetation patches and to select a suitable grid location.

When the grid study area was established, it extended $100 \mathrm{~m}$ along the ecotone and was $45 \mathrm{~m}$ wide. Traps were set at $5 \mathrm{~m}$ intervals. There were two trapping periods during the winter (3-9 December and 19 December - 5 January) and two in the spring (11-28 March and 2-6 April). All trapping periods were arranged so as to avoid periods of especially high tides when portions of the ecotone became flooded.

In order to determine if shrews were moving between the trapping grid on the ecotone and the adjacent grasslands, a $40 \mathrm{~m}$ drift fence was placed in the grass parallel to the ecotone and $25 \mathrm{~m}$ from it. This fence was made of aluminum sheets extending from $5 \mathrm{~cm}$ below ground to $25 \mathrm{~cm}$ above. A total of 16 traps were set on both sides of the fence and at $10 \mathrm{~m}$ intervals (two traps back to back except at ends of fence); they were left open during all trapping periods. No shrews were captured along this fence. Assessment trap lines were also maintained in both directions from the grid and along the ecotone, with 10 traps at $10 \mathrm{~m}$ intervals in each direction. Lines of traps were also occasionally set in the deeper marsh.

Captured animals were toe-clipped for individual identification. They were weighed to the nearest $0.1 \mathrm{~g}$ on a Pesola $10 \mathrm{~g}$ spring scale. Gender was recorded when possible, but remained unknown on some individuals caught only in non-breeding condition. Reproductively active females were apparent by enlarged nipples, and active males by the inguinal bulges of their testes and by the odor of their 
lateral scent glands. Methods recommended by Searle (1985) for determining the sex of subadult Sorex araneus proved ineffective for Suisun shrews except for dissection of trap casualties.

Home ranges were determined by the smallest convex polygon drawn around the captures of individuals caught at least three times in a trapping period (residents). The maximum number of captures in one trapping interval was six. Individuals caught fewer than three times in a trapping period were classified as transients.

\section{Results}

\section{Body mass and reproductive condition}

A total of 161 individual shrews were captured in the ecotone for a total of 711 captures. Of these, 89 were captured on the trapping grid for a total of 528 captures (mean $=5.9$ eaptures per individual). Females in breeding condition had an average body weight of $5.3 \mathrm{~g}$ (3.9-8.9 g), the heaviest individuals being obviously pregnant. Reproductively active males had a mean weight of $6.5 \mathrm{~g}(5.0-9.2 \mathrm{~g})$. Individuals in non-breeding condition averaged $3.7 \mathrm{~g}(2.9-5.6 \mathrm{~g})$. The average weight over all individuals was $5.0 \mathrm{~g}$.

The latest observed pregnancy was on 10 October 1989. One female who died in a trap had five embryos. Two females lactating in September successfully over-wintered, indicating that these two likely bred in the year of their birth. By the end of October, almost all shrews were in non-breeding condition, and by November the loss of external signs of gender or previous reproduction made assignment of unmarked shrews to seasonal cohorts risky. This shift to non-breeding mode was accompanied by a profound loss of body mass. Some loss in average body weight is to be expected as adult shrews die, leaving the over-wintering population dominated by subadults (individuals that have never reached sexual maturity). However, in this case many previously breeding shrews dropped in mass to that of subadults (equals "young adults" of Pucek 1965), demonstrating the Dehnel Effect at least with respect to body size. Mean weight for adult female shrews dropped from 5.3 to $3.7 \mathrm{~g}$ ( $30.2 \%$ decrease) while that of adult males declined from 6.5 to $3.7 \mathrm{~g}$ ( $43.1 \%$ decrease). Assuming that the largest adult males became the largest of the over-wintering cohort, a male at $9.2 \mathrm{~g}$ would have declined to $5.6 \mathrm{~g}(39.1 \%$ decrease), thus supporting the mean weight calculation for weight loss. In spring, the average weight of males increased from 3.7 to $7.8 \mathrm{~g}(210.8 \%)$. One individual was known to have grown from a stable $3.5 \mathrm{~g}$ to a spring weight of $9.0 \mathrm{~g}(257.1 \%)$.

Males began transformation to breeding condition in early March. Females on the other hand remained non-reproductive to the end of the study in mid-April. In early March, no injured shrews were observed, but by the end of this month $15 \%$ of males and at least one subadult were missing toes and/or patches of fur. Two females also had large abrasions and missing fur on the backs of their necks. Males often bite females on the necks during copulation (Martin 1980, Michalak 1983), but in these cases the females did not seem to be yet in breeding condition. In any case, it is clear that a major increase in the level of aggression occurred in this population during March. 


\section{Spatial structure}

Shrews living in the marsh/grassland ecotone exhibited a clumped distribution during both seasons of this study. During the August to October trapping period, six social groups were present along an $1.8 \mathrm{~km}$ stretch of ecotone. Distances between the mid-points of adjacent groups varied from 60 to $440 \mathrm{~m}$ (mean $=288$ $\mathrm{m})$. The exact size of each group is not known because trapping was insufficiently intense for this period. However, the total number of individuals found in each group gives an estimate of the number of individuals that must have interacted regularly in each. This number varied from 5 to 26, and averaged 14.7. Among the four best documented of these six, the resident group consisted of 1 adult male, 1 to 6 adult females, and the rest subadults.

In the winter trapping periods, there were two distinct aggregations of shrews within the trapping grid (Fig. 2). Individuals within an aggregation showed extensive home range overlap, and no individual was caught in both aggregations. Moreover, the membership of each group was quite stable throughout the winter, with most individuals qualifying as residents. Even many of those caught less than
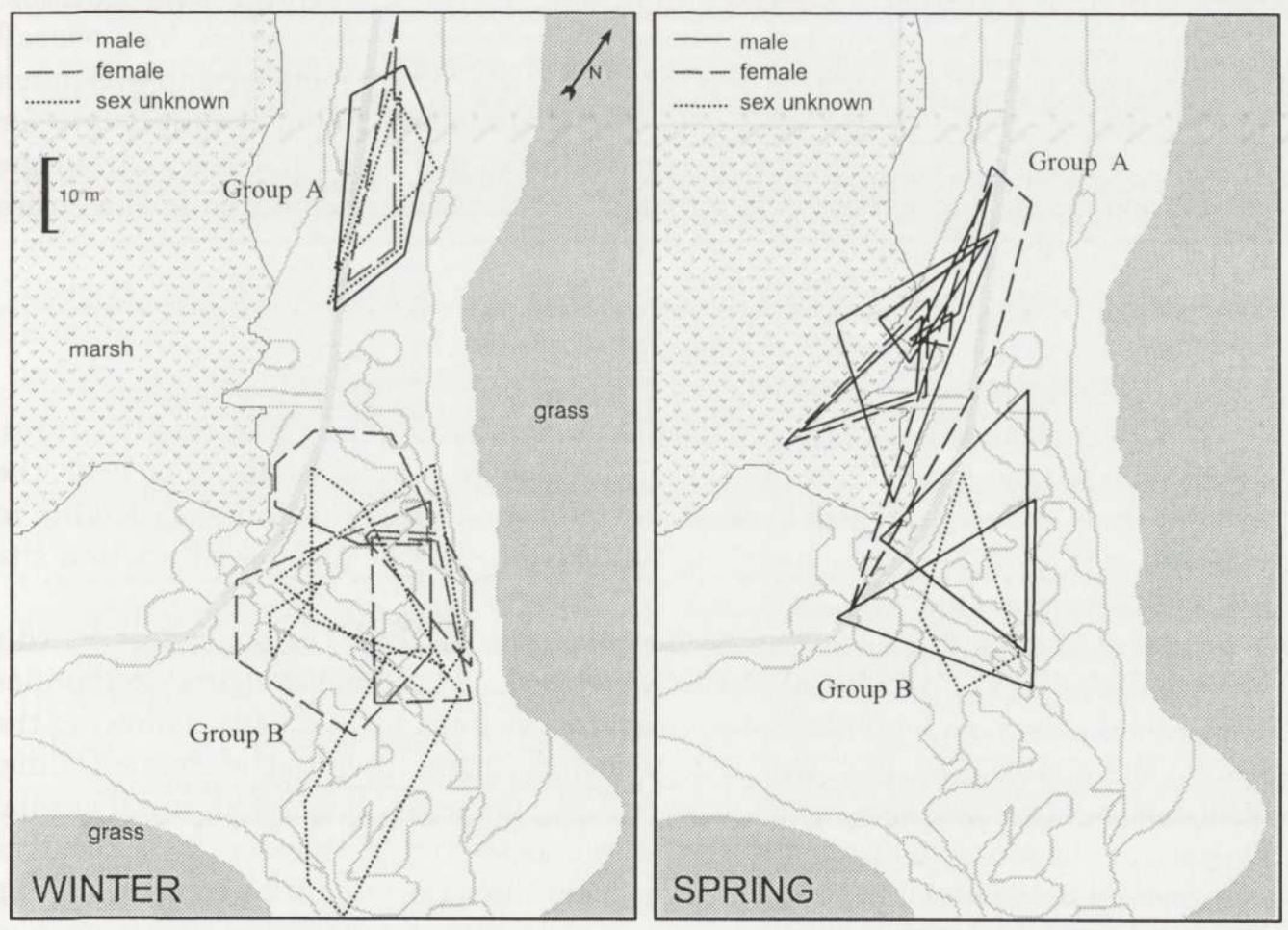

Fig. 2. Winter (left) and spring (right) home ranges of resident shrews (captured three or more times) on the trapping grid plotted as minimum convex polygons. Vegetation patches shown in Fig. 1 are indicated here with light gray lines. 
three times, and hence classified as transients, could have actually been residents. The sex ratio of these groups was $22 \%$ males. There was no obvious barrier in the approximately $15 \mathrm{~m}$ separating the closest edges of the two groups (compare Figs 1 and 2). The centers of the two aggregations were about $60 \mathrm{~m}$ apart.

In one of these social groups, the only known adult male died on 29 September. Within a week, three adult males visited the aggregation but did not remain. A subadult male living about $100 \mathrm{~m}$ away also occasionally visited the group. No other male joined the group for the remainder of the winter. From December through February, this group consisted of 6 to 10 residents, at least 6 of which were known females. Each shrew maintained its relative spatial position in the aggregation in spite of periodic flooding.

In the spring, two groups remained, but they were somewhat closer together (Fig. 2) so that many shrews now lived in places where there were none a few weeks previously. There were also a few incidents in which the same individual was caught within the ranges of both groups. Most importantly, there was a massive change in the membership of the groups. A large influx of new individuals occurred, 46 being caught on the grid at this time. These new arrivals were mostly males $(88 \%)$, predominantly in breeding condition. As in the winter aggregations, members of each new group shared widely overlapping home ranges. The overall sex ratio of these spring aggregations was 77\% male. Group membership was much more dynamic in the spring with only 17 individuals fulfilling requirements for residency. These were $59 \%$ males. The arrival of so many new males equalized the overall population sex ratio. Of 76 individuals of known sex captured in the entire study, $40(52.6 \%)$ were males.

\section{Discussion}

The Suisun shrew population studied here exhibited several unexpected features. Although the study was limited in that it covered only two seasons of one year, the results are dramatic and raise a number of questions about the limits of sociality in soricine shrews. They also extend our observations of the Dehnel Effect to a site without severe winters.

A surprising finding was the occurrence of a marked Dehnel Effect in this population, at least in so far as strongly reduced winter body weights exemplifies this phenomenon. In both sexes, body weights declined by 30 to $40 \%$ following the end of the breeding season. This is equivalent in magnitude to the classic Dehnel Effect shown by Sorex araneus (Pucek 1965, Taylor 1998). It is not known if cranial flattening also occurred in conjunction with these weight changes. This result is unexpected because the Dehnel Effect is generally associated with soricines living in regions with cold winters (Pucek 1970). Although the adaptive significance of these profound morphological and physiological changes is not understood, it is widely assumed that is related to reduced winter food supplies (Taylor 1998). Pucek (1970), however, suggests that it is the small size that is important along with 
associated morphological and physiological changes, and that absolute food intake is not actually decreased. In the Suisun shrew, winters are not severe and food supplies are not obviously decreased, but there may be more instances of enforced fasting by habitat flooding.

Unlike crocidurans, soricine shrews typically are characterized by a spatial structure based on individual territoriality (Rychlik 1998). Well documented examples of the typical soricine sociality include Sorex araneus (Croin Michielsen 1966, Buckner 1969), Sorex minutus (Croin Michielsen 1966, Grainger and Farley 1978), Sorex vagrans and S. obscurus (Hawes 1977), Sorex coronatus (Cantoni 1993), and Neomys fodiens (Cantoni 1993, Krushinska and Rychlik 1994). There are three known exceptions to this pattern, namely, Cryptotis parva (Conaway 1958, McCarley 1959, Getz 1962), Neomys anomalus (Krushinska and Rychlik 1993, Krushinska et al. 1994), and Notiosorex crawfordi (Hoffmeister and Goodpaster 1962). The Suisun shrew must now be added to the small group of species showing social gregariousness. In addition to the two social groups reported in detail here, four other groups were observed during preliminary trapping (Hays 1990).

It remains to be determined if these shrews exhibit grouping behavior in the breeding season as well as the non-breeding period. However, the fact that shrews were in groups at the end of the breeding season (August through October) and again as the breeding season was getting underway (March through April) suggests strongly that this will prove to be the case. A critical issue is whether the observed groups are merely aggregations in favorable micro-habitats or possess some level of social cohesion independently of site. No correlation with vegetation patches was apparent (compare Fig. 1 with 2), and amphipod food resources were abundant throughout the ecotone and in both seasons (Hays 1990). Social cohesion is further implied by the stability of the groups throughout the winter in spite of occasional visitations by other individuals, and in one case following the death of the only adult male in the group. Finally, spaces between groups were sometimes inhabited by non-group members, and in one instance a group shifted into a previously uninhabited space. We can tentatively conclude that social groupings likely occur throughout the year, and that they possess a cohesiveness that is independent of the particular site they inhabit. It must be admitted, however, that micro-habitat selection should be studied in greater detail and throughout the year.

Another major question concerns the whereabouts of most of the males during the winter. The sex ratio of the population as a whole seems to be equal, and yet the composition of the winter groups is strongly female biased. In spring the missing males invade the pre-existing social groups. There is no evidence that males move into the adjacent grasslands which leaves two possibilities. The majority of males may be in the ecotone but outside of social groups, or they may be in the lower marsh. Occasional trapping in these two habitats suggests that both may be true. Although no concentration of males was detected, some non-group males were present along the ecotone and lower in the tidal marsh. The ecotone must have been a minor source, however, as only one of the 72 shrews marked in the autumn 
outside of the grid immigrated on to the grid in spring. Since the tidal marsh floods twice daily, shrews that live there must persist during high tides either in burrows with air pockets or clinging to the emergent vegetation. In either case, this would reduce their foraging time, and possibly increase their exposure to predation. This raises the possibility that group territories in the ecotone are actively defended. However, no evidence of wounding was noted until males came into breeding condition in March, and there were apparently empty regions along the ecotone throughout the winter.

It is perhaps premature to speculate about the possible adaptive significance of the social behavior observed in Suisun shrews. Group huddling for thermoregulatory advantage could be relevant at all seasons as this is a cool environment even in summer. Unlike the situation for most shrews, aggregation may be possible in this case because of the apparent super-abundance of prey. Release from food limitation has been reported to lead to uncommon social complexity in the Egyptian mongoose Herpestes ichneumon (Ben-Yaakov and Yom-Tov 1982). Another possibility is that they may cooperate in the construction and maintenence of the burrow systems in which they live (Hays 1990).

Preliminary as it is, the information presented here should be useful in developing conservation strategies for this unique and endangered shrew. Of particular relevance is our failure to detect any movements of shrews into or out of the adjacent grasslands. This emphasizes what appear to be the unique behavior and physiology of the Suisun shrew, and suggests that interbreeding with the subspecies californicus may be caused by invasion of the marsh by this upland form, and not the reverse. It may be that provision of adequate upland and marsh habitats permits co-existence of both shrews with minimal contact between them.

Acknowledgements: We thank the Solano County Farmlands and Open Space Foundation for allowing us to work on their land. Special appreciation goes to Raine Taylor who assisted with the field work. Trapping was performed under California Department of Fish and Game permit.

\section{References}

Ben-Yaakov R. and Yom-Tov Y. 1982. On the biology of the Egyptian mongoose, Herpestes ichneumon in Israel. Zeitschrift für Säugetierekunde 48: 34-45.

Buckner C. H. 1969. Some aspects of the population ecology of the common shrew, Sorex araneus, near Oxford, England. Journal of Mammalogy 50: 326-337.

Cantoni D. 1993. Social and spatial organization of free-ranging shrews, Sorex coronatus and Neomys fodiens (Insectivora, Mammalia). Animal Behaviour 45: 975-995.

Conaway C. H. 1958. Maintenance, reproduction and growth of the least shrew in captivity. Journal of Mammalogy 39: 507-512.

Croin Michielsen N. 1966. Intraspecific and interspecific competition in the shrews Sorex araneus L. and Sorex minutus L. Archives Néerlandaises de Zoologie 17: 73-149.

Crowcroft P. and Ingles J. M. 1959. Seasonal changes in the brain-case of the common shrew Sorex araneus L.). Nature 183: 907-908.

Dehnel A. 1949. Studies on the genus Sorex L. Annales Universitatis Mariae Curie-Skłodowska, Sectio C4: 17-97. [In Polish with English summary] 
Getz L. L. 1962. A local concentration of the least shrew. Journal of Mammalogy 43: 281-282.

Grainger J. P. and Fairley J. S. 1978. Studies on the biology of the pygmy shrew, Sorex minutus, in the west of Ireland. Journal of Zoology, London 186: 109-141.

Hawes M. L. 1977. Home range, territoriality, and ecological separation in sympatric shrews, Sorex vagrans and Sorex obscurus. Journal of Mammalogy 58: 354-367.

Hays W. S. 1990. Population ecology of ornate shrews, Sorex ornatus. M Sc thesis, University of California, Berkeley: 1-39.

Hays W. S. T. 1998. A new method for live-trapping shrews. Acta Theriologica 43: 333-335.

Hoffmann R. S. 1999. Ornate shrew - Sorex ornatus. [In: The Smithsonian book of North American mammals. D. E. Wilson and S. Ruff, eds]. Smithsonian Institution Press, Washington, DC: 35-36.

Hoffmeister D. H. and Goodpaster W. W. 1962. Life history of the desert shrew Notiosorex crawfordi. Southwestern Naturalist 7: 236-252.

Johnston R. F. and Rudd R. L. 1957. Breeding of the salt-marsh shrew. Journal of Mammalogy 38 : 157-163.

Krushinska N. L. and Rychlik L. 1993. Intra- and interspecific antagonistic behaviour in two sympatric species of water shrews: Neomys fodiens and $N$. anomalus. Journal of Ethology 11: 11-21.

Krushinska N. L. and Rychlik L. 1994. Aggressiveness of a Neomys fodiens parous female towards conspecific and N. anomalus intruders. Acta Theriologica 39: 329-332.

Krushinska N. L., Rychlik L. and Pucek Z. 1994. Agonistic interactions between resident and immigrant sympatric water shrews: Neomys fodiens and $N$. anomalus. Acta Theriologica 39: 227-247.

Martin I. G. 1980. An ethogram of captive Blarina brevicauda. American Midland Naturalist 104: 290-294.

McCarley W. H. 1959. An unusually large nest of Cryptotis parva. Journal of Mammalogy 40: 243.

Michalak I. 1983. Reproduction, maternal and social behaviour of the European water shrew under laboratory conditions. Acta Theriologica 28: 3-24.

Newman J. R. and Rudd R. L. 1978a. Minimum and maximum metabolic rates of Sorex sinuosus. Acta Theriologica 23: 371-380.

Newman J. R. and Rudd R. L. 1978b. Observations of torpor- like behavior in the shrew, Sorex sinuosus. Acta Theriologica 23: 446-448.

Owen J. G. and Hoffmann R. S. 1983. Sorex ornatus. Mammalian Species 212: 1-5.

Pucek Z. 1963. Seasonal changes in the braincase of some representatives of the genus Sorex from the Palearctic. Journal of Mammalogy 44: 523-536.

Pucek Z. 1965. Seasonal age changes in the weights of internal organs of shrews. Acta Theriologica 10: 369-438.

Pucek Z. 1970. Seasonal and age change in shrews as an adaptive process. Symposium of the Zoological Society of London 26: 189-207.

Rudd R. L. 1953. Notes on maintenance and behavior of shrews in captivity. Journal of Mammalogy 34: $118-120$

Rudd R. L. 1955a. Age, sex and weight comparisons in three species of shrews. Journal of Mammalogy 36: $323-338$.

Rudd R. L. 1955b. Population variation and hybridization in some California shrews. Systematic Zoology 4: 21-34.

Rust A. K. 1978. Activity rhythms in the shrews, Sorex sinuosus Grinnell and Sorex trowbridgii Baird. American Midland Naturalist 99: 369-382.

Rychlik L. 1998. Evolution of social systems in shrews. [In: Evolution of shrews. J. M. Wójcik and M. Wolsan, eds]. Mammal Research Institute, Polish Academy of Sciences, Białowieża: 347-406.

Searle J. B. 1985. Methods for determining the sex of common shrews (Sorex araneus). Journal of Zoology, London 206: 279-282.

Taylor J. R. E. 1998. Evolution of energetic strategies in shrews. [In: Evolution of shrews. J. M. Wójcik and M. Wolsan, eds]. Mammal Research Institute, Polish Academy of Science, Białowieża: 309-346. 
Williams D. F. 1983. Population surveys of the Santa Catalina, San Bernardino, and Suisun shrews. United States Department of the Interior, Fish and Wildlife Service, Endangered Species Office, Sacramento, California: 1-69.

Williams D. F. 1986. Mammalian species of special concern in California. Department of Fish and Game, Sacramento, California: 1-112.

Received 17 November 1998, accepted 15 March 2000 